\title{
Urukthapelstatin A, a Novel Cytotoxic Substance from Marine-derived Mechercharimyces asporophorigenens YM11-542
}

\section{Fermentation, Isolation and Biological Activities}

\author{
Yoshihide Matsuo, Kaneo Kanoh, Takao Yamori, Hiroaki Kasai, Atsuko Katsuta, \\ Kyoko Adachi, Kazuo Shin-ya, Yoshikazu Shizuri
}

Received: December 22, 2006 / Accepted: March 9, 2007

(C) Japan Antibiotics Research Association

\begin{abstract}
Urukthapelstatin A, a novel cyclic peptide, was isolated from the cultured mycelia of marine-derived Thermoactinomycetaceae bacterium Mechercharimyces asporophorigenens YM11-542. The peptide was purified by solvent extraction, silica gel chromatography, ODS flash chromatography, and finally by preparative HPLC. Urukthapelstatin A dose-dependently inhibited the growth of human lung cancer $\mathrm{A} 549$ cells with an $\mathrm{IC}_{50}$ value of $12 \mathrm{nM}$. Urukthapelstatin A also showed potent cytotoxic activity against a human cancer cell line panel.
\end{abstract}

Keywords urukthapelstatin A, cyclic peptide, cytotoxic, Thermoactinomyces

\section{Introduction}

In the course of screening for new antibiotic compounds from marine-derived isolates, Mechercharimyces asporophorigenens YM11-542 was found to produce a novel anticancer compound, urukthapelstatin A (1, Fig. 1), which was determined by a spectral analysis and chemical degradation to be a unique cyclic peptide. This peptide possessed potent cytotoxicity against human cancer cell<smiles></smiles>
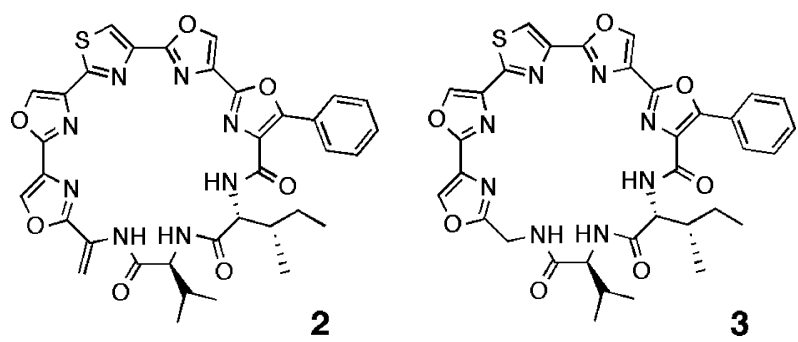

Fig. 1 Structures of urukthapelstatin A (1), mechercharstatin (2; former name, mechercharmycin) and YM-216391 (3).
Y. Matsuo (Corresponding author), K. Kanoh, H. Kasai, A. Katsuta, K. Adachi, Y. Shizuri: Marine Biotechnology Institute Co. Ltd., 3-75-1 Heita, Kamaishi, Iwate 026-0001, Japan,

E-mail: yoshihide.matsuo@mbio.jp

T. Yamori: Division of Molecular Pharmacology, Cancer Chemotherapy Center, Japanese Foundation for Cancer Research, 3-10-6 Ariake, Koto-ku, Tokyo 135-8550, Japan
K. Shin-ya: Chemical Biology Team, Biological Information Research Center (BIRC), National Institute of Advanced Industrial Science and Technology (AIST), 2-42 Aomi, Koto-ku, Tokyo 135-0064, Japan 
lines in vitro, and is structurally related to mechercharstatin (2; former name, mechercharmycin), [1, 2] and YM-216391 (3), [3, 4] which are also potent cytotoxic compounds respectively isolated from the Thermoactinomycetaceae bacterium and Streptomyces. We describe in this paper the fermentation, isolation, and biological activities of $\mathbf{1}$. To evaluate the profile of its anticancer activity in vitro, we used a human cancer cell line panel in combination with a database analysis [5]. The physico-chemical properties and structural determination of $\mathbf{1}$ are described in the subsequent paper [6].

\section{Materials and Methods}

\section{Microorganism and Media}

YM11-542 (M. asporophorigenens, MBIC06487 ${ }^{\mathrm{T}}=\mathrm{DSM}$ $44955^{\mathrm{T}}$ ) was isolated from a sediment sample collected from a marine lake in the northern part of Urukthapel Island in the Republic of Palau. This strain has been reported as a mesophilic member of the novel taxon, Mechercharimyces gen. nov., that is distinguished from members of the related genera in Thermoactinomyces fam. nov. [7].

YM1 1-542 was harvested from marine agar (DIFCO) and used to inoculate 2216 marine broth (MB, DIFCO) to study the antibiotic production. Fermentation was carried out in different modifications of a P2 medium (10 30 g of Pharmamedia (Traders Protein), $1.0 \mathrm{~g}$ of yeast extract, $1.0 \mathrm{~g}$ of sucrose and $0.1 \mathrm{~g}$ of Fe citrate- $\mathrm{nH}_{2} \mathrm{O}$ in $75 \%$ seawater at $\mathrm{pH}$ 7.6). Each culture was incubated at $30^{\circ} \mathrm{C}$ for $5 \sim 14$ days on a rotary shaker at $100 \mathrm{rpm}$. In most cases, $100-\mathrm{ml}$ flasks containing $40 \mathrm{ml}$ of the medium or $1000-\mathrm{ml}$ baffled flasks (Shibata Scientific Technology) containing $500 \mathrm{ml}$ of the medium were used.

\section{Antibiotic Production and HPLC Analysis}

The antibiotic production with the addition of nutrients and beads was studied in duplicate in 100-ml Erlenmeyer flasks with $40 \mathrm{ml}$ of $\mathrm{MB}, 1.0 \mathrm{~g} /$ liter of sucrose containing MB or the P2 medium, and $3.0 \mathrm{ml}$ of HP20 polystyrene divinylbenzene beads (Mitsubishi Chemical Co.) or four types of chitin-based beads (Chitopearl HP3020, SH3503, HP3520 or HP5020; Fujibo Holdings). Each of these flasks was inoculated with $1.0 \mathrm{ml}$ of a 2-day-old culture in MB and incubated at $30^{\circ} \mathrm{C}$ for 10 days. The antibiotic present in the cells and beads was extracted by adding $5.0 \mathrm{ml}$ of $\mathrm{CHCl}_{3} / \mathrm{MeOH}(1 / 1)$ and sonicating for 10 minutes, this being followed by centrifugation $(8,000 \mathrm{rpm}, 15$ minutes $)$ and lyophilization.

The time-course characteristics of antibiotic production were also studied in 1000-ml baffled Erlenmeyer flasks with $500 \mathrm{ml}$ of MB, $1.0 \mathrm{~g} /$ liter of sucrose containing MB or the P2 medium and $30 \mathrm{ml}$ of Chitopearl SH3503. Each of these flasks was inoculated with $10 \mathrm{ml}$ of a 2-day-old culture in $\mathrm{MB}$ and incubated at $30^{\circ} \mathrm{C}$. Three aliquots $(5.0 \mathrm{ml}$ each) from each flask were collected after 5, 7 and 10 days of culture, and the antibiotic present in the cells and beads was extracted in the same manner.

An HPLC analysis was performed with a D-7000 HPLCPDA system (Hitachi), using TSK gel ODS-80Ts (Tosoh). A $100-\mu 1$ aliquot of each sample was directly injected, before centrifuging $(15,000 \mathrm{rpm}, 5$ minutes), eluting with a gradient of $66 \sim 76 \%$ acetonitrile for 10 minutes at a flow rate of $1 \mathrm{ml} /$ minute, and monitoring for 1 ( $\mathrm{rt}=8$ minutes) at UV $290 \mathrm{~nm}$. The production $(\mathrm{mg} / \mathrm{liter})$ of $\mathbf{1}$ was calculated by a standard curve (not shown) from the total area of serially diluted pure 1 on HPLC charts.

\section{Biological Assays}

A549 cells were cultured in Dulbecco's modified Eagle's medium (DMEM) containing 10\% fetal bovine serum. The cells were seeded in a 96-well microplate $(4,000$ cells $/ 200 \mu \mathrm{l} /$ well $)$ and then cultured for 14 hours at $37^{\circ} \mathrm{C}$ in a $\mathrm{CO}_{2}$ incubator $\left(5 \% \mathrm{CO}_{2}\right.$-air). Serially diluted samples were added to each well, and the cells were cultured for a further 48 hours. The number of cells was counted by the Alamar Blue method, and the $\mathrm{IC}_{50}$ value was determined from three independent experiments.

The human cancer cell line panel assay was carried out by the Cancer Chemotherapy Center at the Japanese Foundation for Cancer Research. The precise methods for the experiments and the data analysis have been described elsewhere [5]. The screening panel consisted of the following 39 human cancer cell lines: breast cancer $(\mathrm{Br})$ HBC-4, BSY-1, HBC-5, MCF-7 and MDA-MB-231; brain cancer (CNS) U251, SF-268, SF-295, SF-539, SNB-75 and SNB-78; colon cancer (Co) HCC2998, KM-12, HT-29, HCT-15 and HCT-116; lung cancer (Lu) NCI-H23, NCIH226, NCI-H522, NCI-H460, A549, DMS273 and DMS14; melanoma (Me) LOX-IMVI; ovarian cancer (Ov) OVCAR-3, OVCAR-4, OVCAR-5, OVCAR-8 and SK-OV3; renal cancer (Re) RXF-631L and ACHN; stomach cancer (St) St-4, MKN1, MKN7, MKN28, MKN45 and MKN74; and prostate cancer (xPg) Du-145 and PC-3. The $\mathrm{GI}_{50}$ (50\% growth inhibition), TGI (total growth inhibition) and $\mathrm{LC}_{50}$ values for these cell lines were determined by using the sulforhodamine B (SRB) colorimetric method. Computer processing of these values produced differential activity patterns against the cell lines, from which mean graphs were constructed. These mean graphs were compared with those for standard compounds, including 
(A)
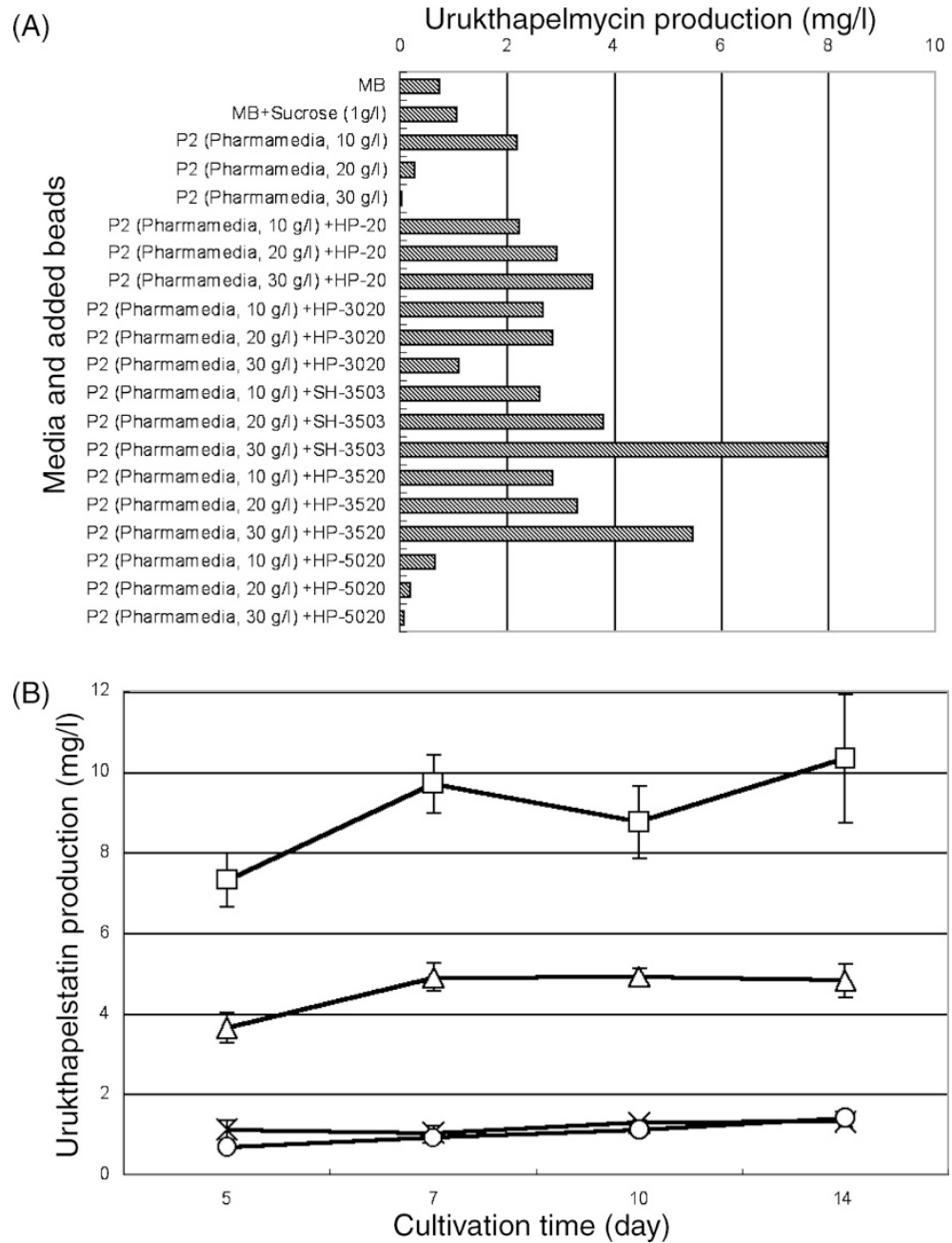

Fig. 2 (A) Antibiotic production in the P2 medium with polymer beads. (B) Time-course characteristics for antibiotic production in the $\mathrm{P} 2$ medium with $\mathrm{SH} 3503$.

$\times$ MB, O MB + Sucrose (1.0 g/liter), $\triangle \mathrm{P} 2$ (Pharmamedia, $30 \mathrm{~g} /$ liter), $\square$ P2 (Pharmamedia, $30 \mathrm{~g} /$ liter) +SH-3503.

various anticancer drugs, by using a COMPARE analysis [5].

\section{Telomerase Inhibition Assay}

Telomerase activity was estimated by Telomeric Repeat Amplification Protocol (TRAP) assay which was the modified version of Kim et al. [8], the details having been described in the previous paper [9].

\section{Results and Discussion}

\section{Antibiotic Production}

Antibiotic production was studied in several complex media, the P2-based medium giving the best results. In order to optimize the production in the P2 medium, we studied the effect of adding Pharmamedia and polymer beads. Concentrations ranging from $1 \sim 3 \%$ of Pharmamedia and five types of beads (HP20, HP3020, SH3503, HP3520 and HP5020) were prepared with the P2 medium, and the antibiotic production after 7 days was analyzed by HPLC (Fig. 2A). The best production without beads was obtained in $1.0 \%$ Pharmamedia. A clear positive effect was observed when beads were then added to the P2 medium. With beads, the best production was obtained in $3.0 \%$ Pharmamedia containing SH3520 beads.

A fermentation time-course study was performed in 1000-ml baffled Erlenmeyer flasks as described in the Materials and Methods section, and the antibiotic present in the cells and beads of 5 14-day cultures was analyzed by HPLC (Fig. 2B). After 7 days, the production of antibiotic in $\mathrm{MB}, \mathrm{MB}+$ sucrose and $\mathrm{P} 2$ with or without the $\mathrm{SH} 3503$ 
beads had almost reached a plateau and remained stable for 14 days of incubation. Maximum production was observed in $\mathrm{P} 2$ (3.0\% Pharmamedia) with the Chitopearl SH3520 beads. The allowable error for $\mathbf{1}$ production by $\mathrm{P} 2$ $(30 \mathrm{~g} /$ liter of Pharmamedia $)+\mathrm{SH} 3520$ in Fig. $2 \mathrm{~B}$ was increased by the number of days of cultivation, resulting in the formation of a protein aggregate of cells and beads. We decided to process the 10 14-day culture as giving acceptable production for antibiotic purification.

\section{Isolation and Purification}

The procedure used for isolating the antibiotic activity is summarized in Fig. 3. After 10 days, the culture (10 liters) was centrifuged, and the mycelial cake and beads were lyophilized. The precipitate was repeatedly extracted with $\mathrm{CHCl}_{3} /$ methanol $(1: 1,1.0$ liter $\times 3$ times $)$. After centrifugation, the organic layer was concentrated under reduced pressure and partitioned between $\mathrm{CHCl}_{3}$ and water, the $\mathrm{CHCl}_{3}$ layer being dried over anhydrous $\mathrm{Na}_{2} \mathrm{SO}_{4}$ and then evaporated to dryness to give a blackish residue $(7.18 \mathrm{~g})$. The extract was chromatographed in a silica gel column with $\mathrm{CHCl}_{3} /$ methanol as the eluent. The fractions containing urukthapelmycin A were eluted with 96:4 $90: 10 \mathrm{CHCl}_{3} /$ methanol and further purified by reversedphase FCC in a Cosmosil 75 C18-OPN column, with methanol/water used as the eluent. Final purification was carried out by $\mathrm{C}_{18}$ preparative HPLC, and the fraction containing 1 was crystallized from $\mathrm{CH}_{2} \mathrm{Cl}_{2} /$ methanol to afford $35 \mathrm{mg}$ of the pure compound.

\section{Biological Activities}

To investigate the profile of the protein's anticancer activity in vitro, we used a human cancer cell line panel combined with a COMPARE analysis $[5,10]$.

1 showed differential growth inhibition, and seemed to be most effective against the lung and ovarian cancer cell lines, the MCF-7, HCT-116, A549, DMS114 and NCI$\mathrm{H} 460$ cell lines with the $\log \mathrm{GI}_{50}$ value between $-8.28 \mathrm{M}$ and $-8.46 \mathrm{M}$. The mean $\log \mathrm{GI}_{50}$ value for $\mathbf{1}$ was $-7.81 \mathrm{M}$, which indicates quite strong activity compared to the anticancer drugs in clinical use on the panel. The COMPARE analysis revealed that $\mathbf{1}$ had a low correlation coefficient with the anticancer reagent cytarabine $(0.636)$ and enocitabine (0.594), respectively. They are all known as antimetabolite antineoplastic agents that inhibit the synthesis of DNA. It has been suggested that YM-216391 and mechercharstatin were DNA synthesis inhibitors by the results of a COMPARE analysis and cell sorting experiments, respectively $[2,3]$.

The effect of 1 on histone deacetylase (HDAC) [11], farnesyl transferase (FPTase) [12] and the proteasome [13]

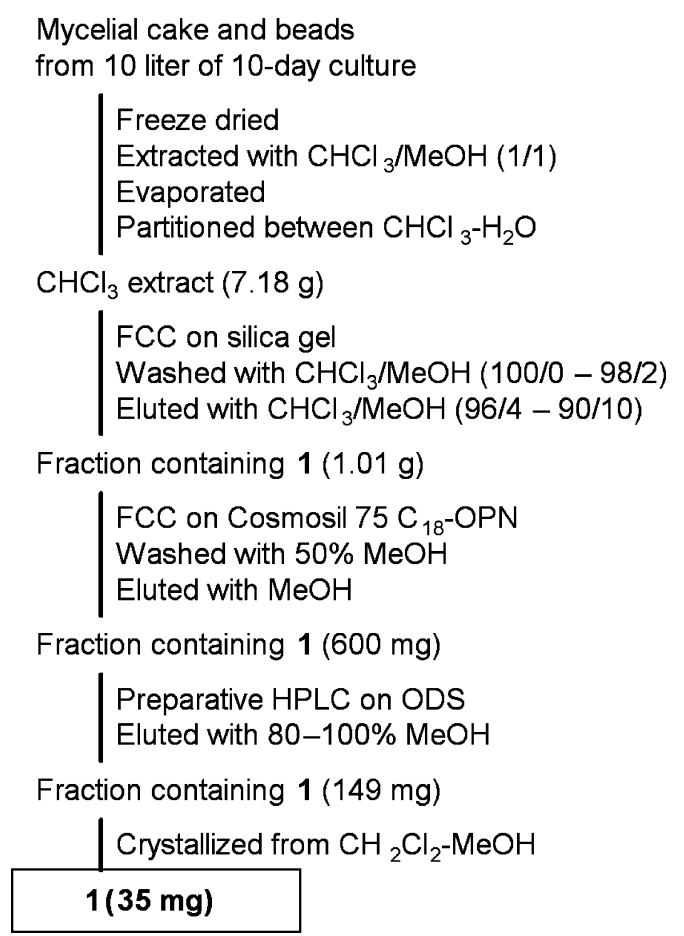

Fig. 3 Procedure for the isolation of $\mathbf{1 .}$

were investigated, but $\mathbf{1}$ did not show any potent activity at $10 \mu \mathrm{M}$.

The telomerase inhibitory activity was also tested, because of the structural similarity to telomestatin, the well-known telomerase inhibitor [14]. However, 1 did not show any telomerase inhibitory activity in TRAP assay at $2 \mu \mathrm{M}$, similar to mechercharstatin [2]. Since, the latest study to develop telomestatin-derivatives disclosed that plane nature of whole compound structure is important to exert telomerase inhibitory activity [15], it should be reasonable that $\mathbf{1}$ did not show inhibitory effects on telomerase.

$\mathbf{1}$ do not exhibited any inhibitory activity against the tested microorganisms (Escherichia coli IFO3301, Bacillus subtilis IFO3134, Staphylococcus aureus IFO12732, and Candida albicans IFO1060) by the paper disc method (10 $\mu \mathrm{g} /$ disc).

The correlation coefficient in the COMPARE analysis was weak, which indicates that $\mathbf{1}$ may have a unique mode of action. Further pharmacological studies and an investigation of the mechanism of action are now underway.

Acknowledgments We are grateful for the technical assistance of Ms. Kumiko Kawahata and Ms. Tomoe Sasaki. We thank the Screening Committee of Anticancer Drugs for support by grantaid for scientific research on priority area "Cancer" from The Ministry of Education, Culture, Sports, Science and Technology, Japan, for the cancer cell line assay, the HDAC assay, the FPTase assay and the proteasome inhibition assay. 
This work was performed as part of the project entitled "Constructing the Genetic Resource Library of Unidentified Microbes Based on Genome Information" supported by New Energy and Industrial Technology Development Organization (NEDO).

\section{References}

1. Kanoh K, Matsuo Y, Adachi K, Imagawa H, Nishizawa M, Shizuri Y. Mechercharmycins A and B, cytotoxic substances from marine-derived Thermoactinomyces sp. YM3-251. J Antibiot 58: 289-292 (2005)

2. Kanoh K, Matsuo Y, Adachi K, Kasai H, Katsuta A, Shizuri Y, Imagawa H, Nishizawa M. Cytotoxic cyclic peptides from marine-derived Firmicutes. 47th Symp Chem Nat Prod 211-216 (2005)

3. Sohda K, Nagai K, Yamori T, Suzuki K, Tanaka A. YM216391, a novel cytotoxic cyclic peptide from Streptomyces nobilis. I. Fermentation, isolation and biological activities. J Antibiot 58: 27-31 (2005)

4. Sohda K, Hiramoto M, Suzumura K, Takebayashi Y, Suzuki K, Tanaka A. YM-216391, a novel cytotoxic cyclic peptide from Streptomyces nobilis. II. Physico-chemical properties and structure elucidation. J Antibiot 58: 32-36 (2005)

5. Yamori T, Matsunaga A, Sato S, Yamazaki K, Komi A, Ishizu K, Mita I, Edatsugi H, Matsuba Y, Takezawa K, Nakanishi O, Kohno H, Nakajima Y, Komatsu H, Andoh T, Tsuruo T. Potent antitumor activity of MS-247, a novel DNA minor groove binder, evaluated by an in vitro and in vivo human cancer cell line panel. Cancer Res 59: 4042-4049 (1999)

6. Matsuo Y, Kanoh K, Imagawa H, Adachi K, Nishizawa M, Shizuri Y. Urukthapelstatin A, a novel cytotoxic substance from marine-derived Mechercharimyces asporophorigenens YM11-542. II. Physico-chemical properties and structural elucidation. J Antibiot 60: 256-260 (2007)

7. Matsuo Y, Katsuta A, Matsuda S, Shizuri Y, Yokota A, Kasai H. Mechercharimyces mesophilus gen. nov., sp. nov. and Mechercharimyces asporophorigenens sp. nov., antitumor substance-producing marine bacteria: proposal for Thermoactinomycetaceae fam. nov. Int $\mathrm{J}$ Syst Evol Microbiol 56: 2837-2842 (2006)

8. Kim NW, Piatyszek MA, Prowse KR, Harley CB, West MD, Ho PLC, Coviello GM, Wright WE, Weinrich SL, Shay JW. Specific association of human telomerase activity with immortal cells and cancer. Science 266: 2011-2015 (1994)

9. Tabata Y, Ikegami S, Yaguchi T, Sasaki T, Hoshiko S, Sakuma S, Shin-ya K, Seto H. Diazaphilonic acid, a new azaphilone with telomerase inhibitory activity. J Antibiot 52: 412-414 (1999)

10. Yaguchi S, Fukui Y, Koshimizu I, Yoshimi H, Matsuno T, Gouda H, Hirono S, Yamazaki K, Yamori T. Antitumor activity of ZSTK474, a novel phosphatidylinositol 3-kinase inhibitor. J Natl Cancer Inst 98: 545-556 (2006)

11. Furumai R, Komatsu Y, Nishino N, Khochbin S, Yoshida M, Horinouchi S. Potent histone deacetylase inhibitors built from trichostatin A and cyclic tetrapeptide antibiotics including trapoxin. Proc Natl Acad Sci USA 98: 87-92 (2001)

12. Takemoto Y, Watanabe H, Uchida K, Matsumura K, Nakae K, Tashiro E, Shindo K, Kitahara T, Imoto M. Chemistry and biology of moverastins, inhibitors of cancer cell migration, produced by Aspergillus. Chemistry \& Biology 12: 1337-1347 (2005)

13. Asai A, Tsujita T, Sharma SV, Yamashita Y, Akinaga S, Funakoshi M, Kobayashi H, Mizukami T. A new structural class of proteasome inhibitors identified by microbial screening using yeast-based assay. Biochem Pharmacol 67: 227-234 (2004)

14. Shin-ya K, Wierzba K, Matsuo K, Ohtani T, Yamada Y, Furihata K, Hayakawa Y, Seto H. Telomestatin, a novel telomerase inhibitor from Streptomyces anulatus. J Am Chem Soc 123: 1262-1263 (2001)

15. Tera M, Sohtome Y, Ishizuka H, Doi T, Takagi M, Shin-ya K, Nagasawa K. Design and synthesis of telomestatin derivatives and their inhibitory activity of telomerase. Heterocycles 69: 505-514 (2006) 